\title{
Substance Use among Undergraduate Students at Mizan-Tepi University in Ethiopia: Prevalence, Associated Factors, and Its Effect on Health and Academic Performance
}

Tewodros Yosef ( $\square$ tewodrosyosef47@mtu.edu.et)

Mizan-Tepi University https://orcid.org/0000-0002-3173-6753

Dawit Getachew

Mizan-Tepi University

\section{Research}

Keywords: Substance Use, Prevalence, Students, Mizan-Tepi University, Ethiopia

Posted Date: November 18th, 2020

DOI: https://doi.org/10.21203/rs.3.rs-105791/v1

License: (c) (1) This work is licensed under a Creative Commons Attribution 4.0 International License. Read Full License 


\section{Abstract}

Background: Worldwide, substance use among undergraduate students is a major public health problem and over 29 million people worldwide suffer from substance-related disorders. The use of substances is a growing concern in Ethiopia, in a particular college and university students are the most at risk of substance use and their impacts on the younger generation have become a great concern. Despite some shreds of evidence are available regarding substance use, the problem is not well studied among these groups of the population. Therefore, this study aimed to assess the prevalence, associated factors, and health and academic effects of substance use among undergraduate students at Mizan-Tepi University in Ethiopia.

Methods: A cross-sectional study was conducted among 544 regular undergraduate students of MizanTepi University in Ethiopia. Data were collected using a pre-tested self-administered structured questionnaire. The data analysis was done using SPSS version 20 . The level of significance in the multivariable logistic regression analysis was declared at a $p$-value $<0.05$.

Results: Of the 544 respondents interviewed, the lifetime and current prevalence of substance use among students in Mizan-Tepi University was $62.5 \%$ and $27.9 \%$ respectively. The most common reported lifetime and current substance use was alcohol drinking with $42.6 \%$ and $23 \%$ respectively. The study also found that being male (AOR=3.01, 95\% $\mathrm{Cl}$ [1.64-5.53]), being Muslim (AOR=3.13, 95\% $\mathrm{Cl}[1.64-5.96])$, from urban residence (AOR=3.12, 95\% $\mathrm{Cl}[3.01-5.31]$ ), having divorced/separated parents (AOR=3.08, 95\% $\mathrm{Cl}[1.64-$ 5.79]), having family substance use (AOR=7.98, 95\% $\mathrm{Cl}[5.52-11.6])$ and peer substance use (AOR=4.33, $95 \% \mathrm{Cl}[2.68-7.26])$ were the factors significantly associated with current substance use.

Conclusion: The current prevalence of substance use was substantially higher. We can say that substance use is a public health problem among university students in Ethiopia. Higher education institutions should consider designing programs to control substance use among students to improve their student's health and academic performance. Parents should closely monitor the behavior of their children by communicating with teachers.

\section{Background}

Substance use refers to the consumption of alcohol or psychoactive drugs not necessarily leading to addiction or dependence (1). The problem of substance use involves at all age levels but appears to be more dangerous and common in adolescence and young adults (2-6) and it affects health, impairs the quality of their life, and as the main source of crime $(7,8)$.

Substance abuse is an ongoing public health concern with an estimated 167-315 million people between the ages of 15-64 use substances globally (9). It became one of the most serious and rapidly growing phenomena, producing many terrible impacts on health, behavioral, and country's economy globally (1013), a particularly high burden in developing countries (14). 
Young people in higher learning institutions are a particularly exposed group in terms of substance use $(15,16)$. The prevalence among university students may be higher compared to the general population (17). Since students generally experience a completely new, unprecedented level of freedom at universities. They are also exposed to a wide range of new practices and choices. These factors help to increase the risk of substance use among university students (18).

Worldwide, substance use among undergraduate students is a major public health problem and over 29 million people suffer from substance-related disorders (19). Academic students are an at-risk population for substance-related problems (20), which negatively affect students' academic performance (21) and harms their mental health (17). At the beginning, substance use seems like a good thing and slowly turned to problem. To comeout from that problem is often difficult. Therefore, the decision to get help is huge and it deserves the maximum support (22).

The factors associated with substance use are varied and may include age, gender, religion, marital status, level of study, feeding out of the university café, being from private preparatory school, getting higher monthly pocket money, parents educational level, low family income, status of parents union, family substance use, peer substance use, easy accessibility of substance, the demise of either or both parents, living without parents and depression $(5,12,30,31,19,23-29)$.

The use of substances is a growing concern in Ethiopia, in a particular college and university students are the most at risk of substance use (26) and their impacts on the younger generation have become a great concern $(24,32)$. Despite some shreds of evidence are available regarding substance use, the problem is not well studied among these groups of the population. Therefore, this study aimed to assess the prevalence, associated factors, and health and academic effects of substance use among undergraduate students at Mizan-Tepi University in Ethiopia.

\section{Methods}

\section{Study design, area, and period}

A cross-sectional study was conducted to assess the prevalence and determinants of substance use among undergraduate students of Mizan-Tepi University (MTU) in Ethiopia from June 1-30, 2018. MizanTepi University was established in 2006 and has two campuses (Mizan campus and Tepi campus). The study was conducted in Tepi campus, which is found in Tepi town, sheka zone at $611 \mathrm{~km}$ and $881 \mathrm{~km}$ southwest of Addis Ababa, the capital city of Ethiopia, and Hawassa, the capital city of South Nations, Nationalities and Peoples Region (SNNPR) respectively. The campus has two colleges, one school, and 15 departments.

\section{Populations}

All regular students of Mizan-Tepi University during the time of data collection were the source population of the study. Those students who studied at Tepi campus were the study population. 


\section{Sample size determination and sampling techniques}

The sample size was determined using a single population proportion formula with the assumption of the prevalence of substance used to be $62.4 \%$ (26), $95 \%$ confidence interval, $5 \%$ margin of error, $10 \%$ for non-response rate and1.5 design effect. The final computed sample size was 595. A multi-stage stratified sampling technique was used. First, the total sample size was proportionally allocated to colleges/school and departments. Then from each department's proportional sample size was allocated for each year level (batch). Finally, a simple random sampling technique was used to select participants in each batch.

\section{Study variables}

The dependent variable was substance use (khat/alcohol/cigarette). The independent variables were age, sex, religion, residence, family income, and educational status of parents, condition of parents, family substance use, and peer substance use.

\section{Operational definitions}

Substance: Any non-medical drugs including alcohol, khat, and tobacco used to alter mood or behavior. Substance use: the use of at least one of the following psychoactive substances (alcohol, khat, cigarettes) to alter mood or behavior. Current use: consuming any substance within the last one month/30 days. Lifetime use: refers to the use of any of the substances at least once in an individual's lifetime. Family substance use: refers to at least one of the family members (father, mother, or siblings) use a substance, who uses at least one of the substances (alcohol, chat, and smoking). Peer substance use: are groups of people of the same age, status, or interests, who use at least one of the substances (alcohol, chat, and smoking).

\section{Data collection instrument and procedures}

The data were collected using a self-administered structured questionnaire adapted from World Health Organization (WHO) students' drug use survey questionnaire $(33,34)$. The questionnaire comprised of socio-demographic characteristics, socio-demographic, and substance use profiles of their family, prevalence of current and lifetime substance use, and substance use-related profiles of the respondents. It was prepared in English to the local language (Amharic) and back to English. The quality of data was assured by properly designing and pre-testing of the questionnaire. The pretest was done on $5 \%$ of the total sample size in Mizan-Aman polytechnic college and a necessary adjustment was made. The training was given to data collectors and supervisors regarding the objective and data collection procedure. All methods were performed in accordance with relevant guidelines and regulations and the data collection was done after ethical issues secured.

\section{Data processing and analysis}

The data were checked for completeness then coded and entered into Epi Data manager software and analyzed using SPSS version 21. Binary logistic regression was employed to identify the association between dependent and expected independent variables. Independent variables significantly associated 
with the dependent variable at a p-value of less than or equals to 0.25 in the bivariate logistic regression model were fitted into the multivariable logistic regression model to control the effect of confounding. Multi-collinearity between independent variables in the model was checked, and the variance inflation factor (VIF) was found acceptable (less than 2). The Hosmer-Lemeshow goodness-of-fit test indicated ( $P$ $=0.341$ ) that the model was good enough to fit the data well.

\section{Results}

\section{Socio-demographic characteristics of the respondents}

Of the 595,544 students participated with a $91.4 \%$ response rate. The mean age was 22 years. The majority (87.5\%) of the respondents were below 24 years old. More than half (52.9\%) were orthodox religious followers. Nearly three-fourths (72.1\%) were achieved GPA between 2.01 to 2.49 in the last semester (Table 1).

Table 1

Socio-demographic characteristics of the respondents at MTU in southwest Ethiopia

\begin{tabular}{|c|c|c|c|}
\hline Variables & Categories & Frequency & Percent \\
\hline \multirow[t]{2}{*}{ Sex } & Male & 358 & 65.8 \\
\hline & Female & 186 & 34.2 \\
\hline \multirow[t]{2}{*}{ Age } & $<24$ years & 476 & 87.5 \\
\hline & $\geq 25$ years & 68 & 12.5 \\
\hline \multirow[t]{3}{*}{ Religion } & Orthodox & 288 & 52.9 \\
\hline & Protestant & 168 & 30.9 \\
\hline & Muslim & 88 & 16.2 \\
\hline \multirow[t]{2}{*}{ Residence } & Rural & 270 & 49.6 \\
\hline & Urban & 274 & 50.4 \\
\hline \multirow[t]{3}{*}{ Last semester GPA } & $<2.00$ & 98 & 18 \\
\hline & $2.01-2.49$ & 392 & 72.1 \\
\hline & $\geq 2.5$ & 54 & 9.9 \\
\hline \multirow[t]{3}{*}{ Respondents belong to } & College of Natural and computational Science & 215 & 39.5 \\
\hline & School of Computer Science & 150 & 27.6 \\
\hline & College of Engineering & 179 & 32.9 \\
\hline
\end{tabular}

Socio-demographic and substance use profiles of the family 
The majority (72.4\%) of parents were living together. Four hundred ninety-three $(90.6 \%)$ and $158(29 \%)$ of the families had < 5000 ETB monthly income and substance use respectively. Of 158 family substance use, 129 (81.3\%) were fathers only (Table 2).

Table 2

Parents socio-demographic and substance use profile of the respondents at MTU in southwest Ethiopia

\begin{tabular}{|llll|}
\hline Variables & Categories & Frequency & Percent \\
\hline Condition of parents & Living together & 390 & 71.7 \\
\cline { 2 - 4 } & Divorced/separated & 118 & 21.7 \\
\cline { 2 - 4 } Educational status of parents & Either one or both parents died & 36 & 6.6 \\
\cline { 2 - 4 } & No formal education & 90 & 16.5 \\
\cline { 2 - 4 } Family monthly income & Formal education & 454 & 83.5 \\
\hline Family substance abuse & $<5000$ & 493 & 90.6 \\
\cline { 2 - 4 } & $\geq 5000$ & 51 & 9.4 \\
\hline Family members used $(\mathrm{n}=158)$ & Yes & 158 & 29 \\
\cline { 2 - 4 } & Fother only & 386 & 71 \\
\cline { 2 - 4 } & Mother only & 129 & 81.6 \\
\cline { 2 - 4 } & Both parents & 9 & 5.7 \\
\cline { 2 - 4 } & Siblings & 8 & 5.1 \\
\hline
\end{tabular}

\section{Prevalence of lifetime and current substance use}

The lifetime and current prevalence of substance use among students at Mizan-Tepi University was $62.5 \%$ and $27.9 \%$ respectively. The most common reported lifetime and current substance use was alcohol drinking with $42.6 \%$ and $23 \%$ respectively (Fig. 1).

\section{Substance use-related profiles among user respondents}

Nearly three-fourths $(72.4 \%)$ of the respondents used substances for 2 years or more. One hundred-eight (71.1\%) used substances at the rented house outside the university campuses. More than one-third (36.8\%) of the respondents mentioned peer influence as a reason for their current substance use. Of the 152 current substance users, 96 (63.2\%) had oral/gastric problems followed by 78 (51.3\%) and 58 $(38.2 \%)$ had a frequent loss of appetite and absenteeism in class after taking substances respectively (Table 3). 
Table 3

Substance use related profiles among user respondents at MTU in southwest Ethiopia

\begin{tabular}{|c|c|c|c|}
\hline Variables & Categories & Frequency & Percent \\
\hline \multirow[t]{3}{*}{ Age at first experimentation (years) } & $<15$ & 6 & 4 \\
\hline & $15-20$ & 70 & 46 \\
\hline & $\geq 20$ & 76 & 50 \\
\hline \multirow[t]{3}{*}{ Duration of abuse (years) } & $<1$ & 10 & 6.5 \\
\hline & $1-2$ & 32 & 21.1 \\
\hline & $\geq 2$ & 110 & 72.4 \\
\hline \multirow[t]{4}{*}{ Abuse frequency } & Daily & 54 & 35.5 \\
\hline & Every other day & 43 & 28.3 \\
\hline & Once a week & 25 & 16.5 \\
\hline & Once a month & 30 & 19.7 \\
\hline \multirow[t]{3}{*}{ Place of substance use } & At dormitory & 18 & 11.8 \\
\hline & At grocery/cinema & 26 & 17.1 \\
\hline & At rented house & 108 & 71.1 \\
\hline \multirow[t]{4}{*}{ Reason for substance use } & Peer influence & 56 & 36.8 \\
\hline & To get relief from stress & 22 & 14.5 \\
\hline & To stay awake for reading & 44 & 29 \\
\hline & To entertain & 30 & 19.7 \\
\hline \multirow[t]{8}{*}{ Effects of substance use $(n=152)$} & Oral/ gastric problem & 96 & 63.2 \\
\hline & Loss of appetite & 78 & 51.3 \\
\hline & Absenteeism in class & 58 & 38.2 \\
\hline & Difficulty of learning & 38 & 25 \\
\hline & Sleep problem & 35 & 23 \\
\hline & Sexual problem & 32 & 21.1 \\
\hline & Decrease performance & 30 & 19.7 \\
\hline & Depression/anxiety & 26 & 17.1 \\
\hline \multirow[t]{2}{*}{ Plan to substance use } & To continue & 22 & 14.5 \\
\hline & To stop & 44 & 29 \\
\hline
\end{tabular}




\begin{tabular}{|llll|}
\hline Variables & Categories & Frequency & Percent \\
\hline & I don't know & 86 & 56.5 \\
\hline
\end{tabular}

\section{Factors associated with substance use}

After running a multivariable logistic regression analysis, being male ( $A O R=3.01,95 \% \mathrm{Cl}[1.64-5.53])$, being Muslim ( $A O R=3.13,95 \% \mathrm{Cl}[1.64-5.96])$, from urban residence $(\mathrm{AOR}=3.12,95 \% \mathrm{Cl}[3.01-5.31])$, having divorced/separated parents (AOR $=3.08,95 \% \mathrm{Cl}[1.64-5.79])$, having family substance use (AOR $=7.98,95 \% \mathrm{Cl}[5.52-11.6])$ and peer substance use (AOR $=4.33,95 \% \mathrm{Cl}[2.68-7.26])$ were the factors significantly associated with current substance use (Table 4). 
Table 4

Factors associated with substance use among respondents at MTU in southwest Ethiopia.

\begin{tabular}{|c|c|c|c|c|c|c|}
\hline \multirow[t]{2}{*}{ Variables } & \multirow[t]{2}{*}{ Categories } & \multicolumn{2}{|c|}{$\begin{array}{l}\text { Substance } \\
\text { abuse }\end{array}$} & \multirow[t]{2}{*}{ COR $(95 \% \mathrm{Cl})$} & \multirow[t]{2}{*}{$\begin{array}{l}\text { AOR }(95 \% \\
\mathrm{Cl})\end{array}$} & \multirow[t]{2}{*}{$\begin{array}{l}\mathrm{P} \text { - } \\
\text { value }\end{array}$} \\
\hline & & Yes & No & & & \\
\hline \multirow[t]{2}{*}{ Sex } & Female & 20 & 166 & 1 & 1 & \\
\hline & Male & 132 & 226 & $\begin{array}{l}4.85(2.01- \\
6.42)^{\star \star}\end{array}$ & $\begin{array}{l}3.01(1.64- \\
5.53)\end{array}$ & $\begin{array}{l}< \\
0.001\end{array}$ \\
\hline \multirow[t]{2}{*}{ Religion } & Christianity & 76 & 281 & 1 & 1 & \\
\hline & Muslim & 76 & 111 & $\begin{array}{l}2.53(1.72- \\
3.73)^{\star \star}\end{array}$ & $\begin{array}{l}3.13(1.64- \\
5.96)\end{array}$ & 0.001 \\
\hline \multirow[t]{2}{*}{ Residence } & Rural & 42 & 228 & 1 & 1 & \\
\hline & Urban & 110 & 164 & $\begin{array}{l}3.64(2.42- \\
5.48)^{\star \star}\end{array}$ & $\begin{array}{l}3.12(3.01- \\
5.31)\end{array}$ & $\begin{array}{l}< \\
0.001\end{array}$ \\
\hline \multirow{3}{*}{$\begin{array}{l}\text { Condition of } \\
\text { parents }\end{array}$} & Living together & 84 & 306 & 1 & 1 & \\
\hline & Divorced/separated & 60 & 58 & $\begin{array}{l}3.60(2.34- \\
5.54)^{\star \star}\end{array}$ & $\begin{array}{l}3.08(1.64- \\
5.79)\end{array}$ & $\begin{array}{l}< \\
0.001\end{array}$ \\
\hline & $\begin{array}{l}\text { Either one or both } \\
\text { died }\end{array}$ & 8 & 28 & $\begin{array}{l}0.50(0.17- \\
1.45)^{\star}\end{array}$ & $\begin{array}{l}0.96(0.26- \\
3.61)\end{array}$ & 0.952 \\
\hline \multirow[t]{2}{*}{$\begin{array}{l}\text { Family substance } \\
\text { use }\end{array}$} & Yes & 94 & 64 & $\begin{array}{l}8.31(5.44- \\
12.7)^{\star \star}\end{array}$ & $\begin{array}{l}7.98(5.52- \\
11.6)\end{array}$ & $<.001$ \\
\hline & No & 58 & 328 & 1 & 1 & \\
\hline \multirow{2}{*}{$\begin{array}{l}\text { Peer substance } \\
\text { use }\end{array}$} & No & 50 & 284 & 1 & 1 & \\
\hline & Yes & 102 & 108 & $\begin{array}{l}5.36(3.67- \\
8.55)^{\star \star \star}\end{array}$ & $\begin{array}{l}4.33(2.68- \\
7.26)\end{array}$ & $\begin{array}{l}< \\
0.001\end{array}$ \\
\hline
\end{tabular}

\section{Discussion}

This study aimed to assess the prevalence, associated factors, and health and academic effects of substance use among undergraduate students at Mizan-Tepi University in Ethiopia. The prevalence of substance use among undergraduate students was $27.9 \%, 95 \% \mathrm{Cl}(24.1 \%-31.7 \%)$. This finding was consistent with $31.5 \%$ in Haramaya University (11) and 28.6\% in Woliyta Sodo University (35) in Ethiopia, $31 \%$ in Sudan (14), and $29.1 \%$ in Imo state, Nigeria(19). It was lower than $43 \%$ in Jima University (36) and 46.3\% in Debre Markos university (31) in Ethiopia. But it was higher than $16.7 \%$ in Adigrat University, Ethiopia (37), 17.5\% in Nigeria (38), and 20.3\% in Myanmar(29). The variation observed between the 
current and previous studies could be the difference in the sample size, operational definition used, and the methodology as a whole. Besides, the socio-demographic, socio-economic, and lifestyle or behavioral factors difference between different population groups may create a great variation.

In this study, sex was significantly associated with substance use. Being male was 3 times increased odds of substance use than being women. This finding was in line with several studies conducted elsewhere $(5,11,30,31,39,12,19,23,25-29)$. This could be because males are more likely to experiment with things in their life. The attitude of the community that considers female substance use as taboo and male substance use is not considered a big issue.

Respondents who are Muslim were 3 times increased odds of substance use behavior than Christianity followers. Being Muslim was significantly associated with substance use behavior. This finding was contrary to a study done at Haramaya University, Ethiopia (26). Despite, alcohol consumption was common among Christian students. However, the prevalence of chat chewing was high among Muslims. Since using at least one of substances (alcohol, chat, and cigarette) operationalized as a user of substance in this study. The increased prevalence of chat chewing among Muslims results in the high likelihood of Muslim students classified as substance users. This could be the reason for the variation observed between this study and the previous study in Ethiopia.

Respondents who come from urban residences were 3 times more likely to use substances than those who came from rural areas. Being an urban resident was statistically associated with substance use behavior. This could be the fact that students who came from urban areas are more likely to familiarize with substances (either using or observing someone use substance) due to the more accessibility of substance in urban than rural areas.

In this study having divorced or separated parents was significantly associated with student's substance use behavior. Respondents who had divorced or separated parents were 3 times more likely to use substances than those who had parents living together. This finding was consistent with a study done in Imo State, Nigeria (19). This could be explained by those students who had divorced/ separated parents who didn't get parental restriction and no one care for them to be disciplined. Besides, those individuals are more likely to become hopeless and depressed that prone them to experiment with substance to relieve their problem. Since an individual who had a feeling of hopelessness or sadness and depression are more likely to use the substance $(26,29,39)$.

Respondents who had family member substance use were 8 times increased odds of substance use than those who didn't have. Having substance used family members was very strongly associated with the respondent's substance use behavior. This finding was consistent with previous studies done elsewhere $(5,11,24-28)$. This could be the fact that children follow the behavior of their family. Since children are followed the footsteps of their families, any behavior that is performed within the family may be easily followed by children. 
In this study, having a peer with substance abuse was strongly associated with the substance use behavior of the respondents. Respondents who had peer substance user were 4.3 times more likely to use substance than who don't have a peer with substance use. This finding was in line with previous studies conducted elsewhere $(5,24,27-29)$. This could be because students may borrow or seem friend behavior. Any behavior of their friends may influence their behavior greatly.

\section{Limitation Of The Study}

The authors acknowledge some limitations in this study. The depression and anxiety variables were not measured using a standard tool, rather the researchers use single-item questions for each variable to assess the conditions happen. Besides, the cross-sectional nature (snapshot approach of data collection) of the study design didn't allow ascertaining the case-effect relationship between the dependent and independent variables.

\section{Conclusion}

The current prevalence of substance use was substantially higher. We can say that substance use is a public health problem among university students in Ethiopia. Higher education initiations should consider designing programs to control substance use among students to improve their student's health and academic performance. Parents should closely monitor the behavior of their children by communicating with teachers.

\section{Abbreviations}

AOR: Adjusted Odds Ratio, Cl: Confidence Interval, COR: Crude Odds Ratio, MTU: Mizan- Tepi University, SPSS: Statistical Package for Social Sciences

\section{Declarations}

\section{Ethics approval and consent to participate}

Ethical approval was obtained before starting data collection from Mizan-Tepi University Institutional Review Board (MTU-IRB). All study participants were informed about the purpose of the study, their right to deny participation, anonymity, confidentiality of the information. Written informed consent was also obtained before participation in the study.

Consent for publication: Not applicable.

Availability of data and materials: The data set is handled by the corresponding author and can be provided upon request.

Conflict of interest: The authors declare no conflicts of interest. 
Funding: Not applicable

Authors' contributions: TY and DG are involved in the conception, design, acquisition of data, analysis, and interpretation of the results. TY drafted the manuscript, and then all authors approved it for publication.

\section{Acknowledgment}

First, we would like to thank all study participants for their participation. Second, our thank goes to academic and administrative staff at Mizan-Tepi University who gave us full collaboration during the study period.

\section{References}

1. Njoroge MW. Journal of Alcoholism \& Drug Knowledge, Attitude and Practices on Substance Use Disorders by University Students: A Review of Literature. J Alcohol Drug Depend. 2017;5(6):1-5.

2. Tshitangano TG TO. Substance use amongst secondary school students in a rural setting in South Africa: prevalence and possible contributing factors. Afr J Prim Heal Care Fam Med. 2016;8(2):e1-6.

3. Webb E, Ashton $\mathrm{CH}$, Kelly P, Kamali F. Alcohol and drug use in UK university students. Lancet. 1996;348(10):922-5.

4. Clowdus CM. Substance Use Among College Students: Correlations with Intent to Graduate , Academic Integration, and Social Integration. Digital Commons @ ACU, Electronic Theses and Dissertations. 2016.

5. Shahabuddin ASM, Brouwere V De, Adhikari R, Delamou A, Bardaj A, Delvaux T. Determinants of institutional delivery among young married women in Nepal: Evidence from the Nepal Demographic and Health Survey , 2011. BMJ Open. 2017;7:e012446.

6. Nižić M, Tanja Penava, Ines Perić. The prevalence of substance use among first-year students at the University of Mostar , Bosnia and Herzegovina. J Educ Cult Soc. 2013;29(1):83-94.

7. Kounenou K. Exploration of the relationship among drug use \& alcohol drinking , entertainment activities and self-esteem in Greek University students. Procedia Soc Behav Sci. 2010;2(2):1906-10.

8. Coleman F. Essien. Drug Use and Abuse among Students in Tertiary Institutions - The Case of Federal University of Technology, Minna. J Res Natl Dev. 2010;8(1).

9. World drug Report. Division for Policy Analysis and Public Affairs United Nations Office on Drugs and Crime. 2013.

10. Gaete J, Rojas G, Fritsch R, Araya R. Association between School Membership and Substance Use among Adolescents. Front Psychiatry. 2018;9:25.

11. Alebachew W, Semahegn A, Ali T, Mekonnen H. Prevalence, associated factors and consequences of substance use among health and medical science students of Haramaya University, eastern Ethiopia , 2018: a cross-sectional study. BMC Psychiatry. 2019;19:343. 
12. Rabie M, Shaker NM, Gaber E, El-habiby M, Ismail D, El-gaafary M, et al. Prevalence updates of substance use among Egyptian adolescents. Middle East Curr Psychiatry. 2020;27:4.

13. Odejide AO. Status of drug use/abuse in Africa. Int J Ment Health. 2006;4:87-102.

14. Osman T, Victor C, Abdulmoneim A, Mohammed H, Abdalla F, Ahmed A, et al. Epidemiology of Substance Use among University Students in Sudan. J Addict. 2016;2016.

15. Teferra S. Substance use among university students in Ethiopia: A systematic review and metaanalysis. EthiopJHealth Dev. 2018;32(4):265-77.

16. World Health Organization. Global status report on alcohol and health 2018. Geneva: World Health Organization. 2018.

17. Kalayu M, Andualem M YG. Effect of substance use on academic achievement of health officer and medical students of Jimma University, Southwest Ethiopia. Ethiop J Heal Sci. 2009;19:155-63.

18. Bunch J. Substance Abuse and Academic Performance Among University Students Substance Abuse and Academic Performance Among University Students. Catal. 2002;1(2).

19. Duru CB, Oluoha UR, Okafor CC, Diwe KC, Iwu AC, Aguocha CM, et al. Socio-Demographic Determinants of Psychoactive Substance Use among Students of Tertiary Institutions in Imo State, Nigeria. J Addict Res Ther. 2017;8(5):1-9.

20. Simons JS, Gaher RM, Correia CJ, Hansen CL CM. An affective-motivational model of marijuana and alcohol problems among college students. Psychol Addict Behav. 2005;19(3):326-34.

21. Mekonen T, Fekadu W, Mekonnen TC, Workie SB. Substance Use as a Strong Predictor of Poor Academic Achievement among University Students. Psychiatry Journa. 2017;2017:7517450.

22. Dennis DK. Substance Abuse in College: Recognizing, Understanding and Combatting Alcohol \& Drug Abuse on Campus. 2020.

23. Wagner GA, Stempliuk VDA, Zilberman ML, Barroso LP, Andrade AG De. Alcohol and drug use among university students: gender differences. Rev Bras Psiquiatr. 2007;29(2):123-9.

24. Gobeje A, Measo G AA and CT. Prevalence of Substance Use and Associated Factors Among Preparatory Students of N/Wollo Woldia Town, North East Ethiopia, 2015. ACTA Sci Nutr Heal. 2019;3(2):25-33.

25. Fareo DO. Drug abuse among Nigerian adolescents: Strategies for counseling. J Int Soc Res. 2012;20:52.

26. Tesfaye G, Derese A, Hambisa MT. Substance Use and Associated Factors among University Students in Ethiopia: A Cross-Sectional Study. J Addict. 2014;2014.

27. Gebremariam TB, Mruts KB, Neway TK. Substance use and associated factors among Debre Berhan University students, Central Ethiopia. Subst Abuse Treat Prev Policy. 2018;13:13.

28. Kabir K, Mohammadpoorasl A, Esmaeelpour R, Aghazamani F. Tobacco Use and Substance Abuse in Students of Karaj Universities. Int J Prev Med. 2016;7:105.

29. Htet H, Mon YS, Saw TN, Mie N, Htun M, Lay K, et al. Prevalence of alcohol consumption and its risk factors among university students: A cross-sectional study across six universities in Myanmar. PLoS 
One. 2020;15(2):e0229329.

30. Cranford JA, Eisenberg D, Serras AM. Addictive Behaviors Substance use behaviors, mental health problems, and use of mental health services in a probability sample of college students. Addict Behav. 2009;34(2):134-45.

31. Tsegay G, Esmael A. Psychoactive Substances Use (Khat, Alcohol and Tobacco) and Associated Factors among Debre Markos University Students, North-West Ethiopia, 2013. J Def Manag. 2014;4(1):1-7.

32. Roba HS, Beyene AS, Irenso AA, Gebremichael B. Prevalence of lifetime substances use among students in Ethiopia: a systematic review and meta-analysis. Syst Rev. 2019;8:326.

33. The ASSIST project - Alcohol, Smoking and Substance Involvement Screening Test. https://www.who.int/substance_abuse/activities/assist/en/.

34. The reliability and validity of the WHO student drug-use questionnaire among Nigerian students. https://www.ncbi.nlm.nih.gov/pubmed/2606001.

35. Mekonen T, Fekadu W, Mekonnen TC, Workie SB. Substance Use as a Strong Predictor of Poor Academic Achievement among University Students. Psychiatry J. 2017;2017:7517450.

36. Desta E, Soboka M, Workneh D, Bosena Gashaw T. The Prevalence of Substance Use and Associated Factors Among Medical Interns of Jimma University, South West Ethiopia. J Subst Abus Alcohol. 2018;6(1):1-8.

37. Mossie TB, Gebremichael GB, Ayele AD. Magnitude of Psychoactive Substance Abuse among University Students, Adigrat, North Ethiopia: Cross Sectional Study. J Psychiatry. 2015;18(4):1-4.

38. Idowu AA, Somefun OD. Recreational drug use among Nigerian university students: Prevalence, correlates and frequency of use. PLoS One. 2020;15(5):e0232964.

39. Mahmood N, Othman S, Al-tawil N, Al-hadithi T. Substance use among high school students in Erbil City , Iraq: prevalence and potential contributing factors. East Mediterr Heal J. 2019;25(11):806-12.

\section{Figures}




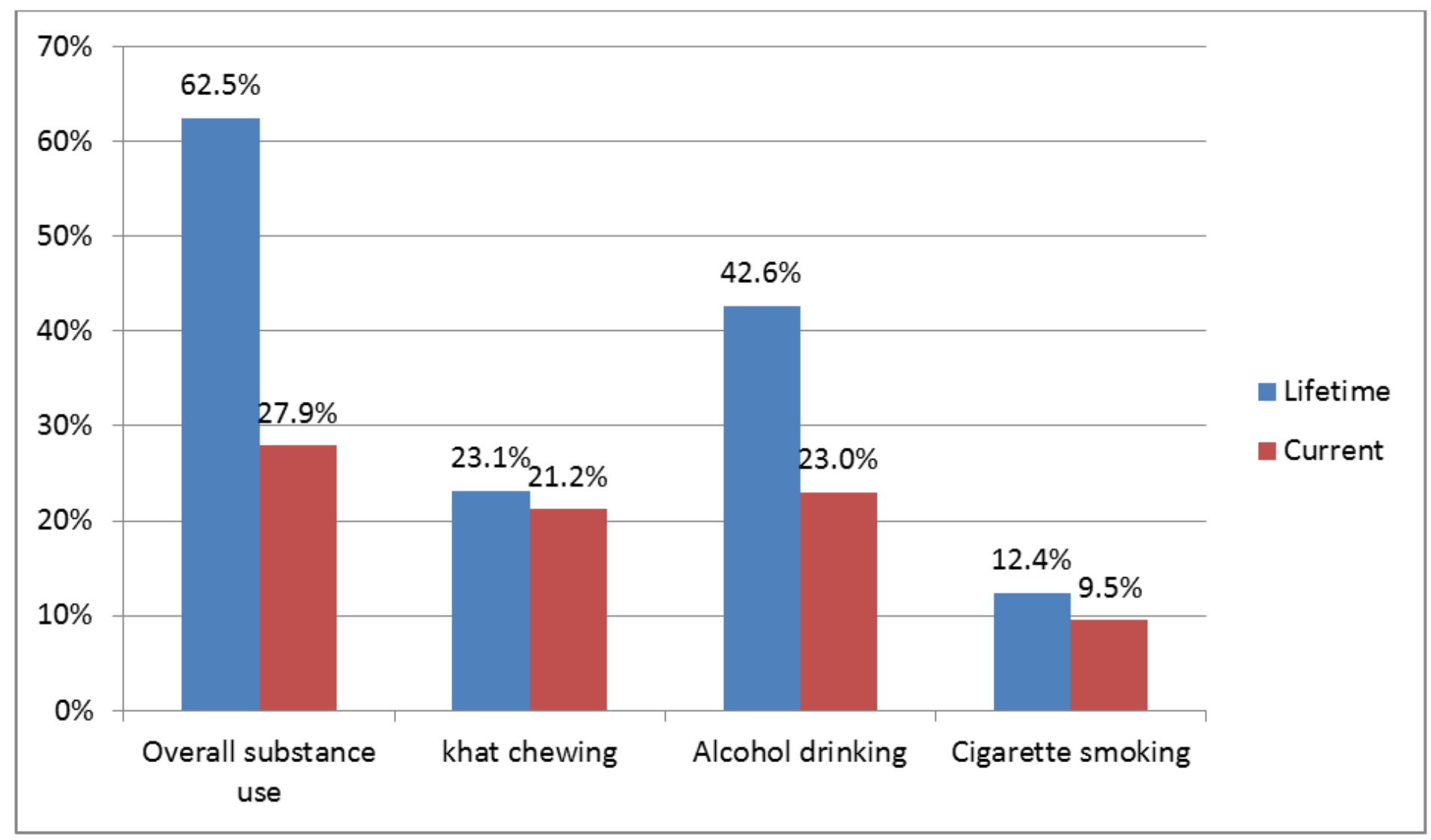

\section{Figure 1}

Prevalence of lifetime and current substance use among respondents at MTU in southwest Ethiopia. 


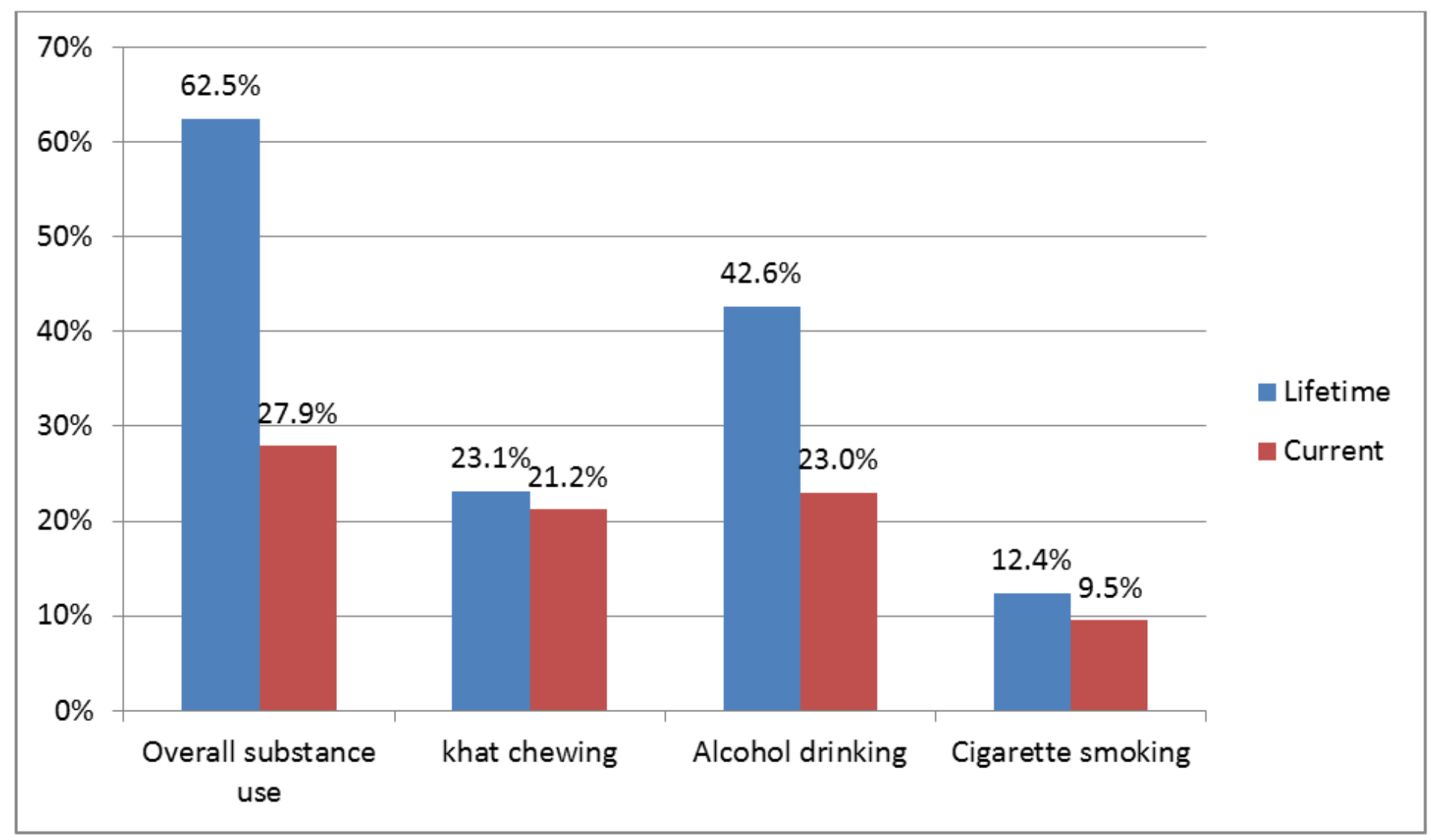

\section{Figure 1}

Prevalence of lifetime and current substance use among respondents at MTU in southwest Ethiopia. 